Edwin Cruz Rodriguez**

Universidad Nacional de Colombia, Bogotá, Colombia.

Recibido: 10 de marzo de 2014

Concepto de evaluación: 17 de junio de 2014

Aprobado: 18 de junio de 2014

Artículo de reflexión (C) 2014 Universidad Católica de Colombia. Facultad de Ciencias Económicas y Administrativas. Todos los derechos reservados

* Candidato a doctor en Estudios Políticos y Relaciones Internacionales, de la Universidad Nacional de Colombia. Profesor ocasional del Departamento de Ciencia Política de la Universidad Nacional de Colombia. Correo postal: Av, Carrera 30 No. 45-03, edificio Manuel Ancízar, oficina 1009, Bogotá, Colombia. Correo electrónico: ecruzr@unal.edu.co

\section{Prolegómenos al vivir bien-buen vivir: una evaluación normativa y práctica}

\section{RESUMEN}

Este trabajo examina el concepto de vivir bien-buen vivir ponderando sus contribuciones y limitaciones. Esta cosmovisión tiene un horizonte normativo más ambicioso que el paradigma del desarrollo, pues apuesta por una concepción de la pobreza y la riqueza que no se reduce a la acumulación de bienes materiales, una economía que comprende sus efectos sobre la naturaleza y se centra en la satisfacción de necesidades, y una descolonización de los saberes. No obstante, se caracteriza por un déficit de operacionalización que se manifiesta en la dificultad para definir políticas concretas e indicadores de medición precisos.

Palabras clave: vivir bien, buen vivir, desarrollo, política económica, América Latina.

JEL: B59

\section{Prolegomena to live well-good living: A normative and practical evaluation}

\section{ABSTRACT}

This article examines the concept of live well-good living, by analyzing its contributions and limitations. This worldview has a normative horizon more ambitious than the development paradigm, as it wagers for a poverty and wealth conception that is not limited to the accumulation of material goods, but it is an economy aware of its effects on nature and the satisfaction of needs and the decolonizing of knowledge. Nevertheless, it is characterized by an operationalization deficit that is shown through the difficulty to establish specific policies and accurate indicators of measurement.

Keywords: Live well, good living, development, political economy, Latin America. 


\section{Prolegômenos ao viver bem-bom viver: uma avaliação normativa e prática}

\section{RESUMO}

Este trabalho examina o conceito de viver bem-bom viver ponderando suas contribuições e limitações. Essa cosmovisão tem um horizonte normativo mais ambicioso do que o paradigma do desenvolvimento, pois aposta por uma concepção da pobreza e da riqueza que não se reduz à acumulação de bens materiais, uma economia que compreende seus efeitos sobre a natureza e centra-se na satisfação de necessidades, e uma descolonização dos saberes. Contudo, caracateriza-se por um déficit de operacionalização que se manifesta na dificuldade para definir políticas concretas e indicadores de medição precisos.

Palavras-chave: viver bem, bom viver, desenvolvimento, política econômica, América Latina. 


\section{INTRODUCCIÓN}

En los últimos años, sobre todo desde las reformas constitucionales de Bolivia (2009) y Ecuador (2008), que reconocieron las cosmovisiones andinas del vivir bien y del buen vivir (en adelante VBBV), respectivamente, como alternativas a lo que habitualmente se denomina el "modelo de desarrollo", estos conceptos han incursionado en los debates sobre políticas públicas y economía pública. ${ }^{1}$ Según esta perspectiva, el desarrollo, tomado como un paradigma de "vida buena" más que como un conjunto de enfoques teóricos, ha llegado a sus límites. Esa idea de vida buena se ha basado en el crecimiento económico, la producción y el consumo ilimitados, posibilitados por el aprovechamiento de la energía proveniente de la explotación de minerales fósiles y, en general, de la extracción de todo tipo de recursos naturales. Como cosecuencia, se ha generado una crisis ambiental sin precedentes, que amenaza las posibilidades de la vida en el planeta y que se expresa en el cambio climático debido a las enormes emisiones de dióxido de carbono, la superación de los límites de la huella ecológica tolerables para la resiliencia de la biósfera, la pérdida irreparable de biodiversidad y la modificación del ciclo del nitrógeno, entre otros (Dietz, 2013, p. 473; Sempere, 2009; Lovelock, 2011).

En América Latina, esta situación se ha agravado con el auge del denominado "modelo extractivista" en los últimos años. Si bien la región

1 La nueva Constitución Política boliviana, ratificada en enero de 2009, mediante referéndum popular por el $61,43 \%$ asume y promueve los principios ético-morales de la sociedad plural y del vivir bien o suma qamaña, en aymara (art. 8. I.). Por su parte, la nueva Constitución Política ecuatoriana, también ratificada mediante referéndum en octubre de 2008 por el $63,86 \%$ de votos, en su parte dogmática y en el título VI incorpora aspectos de la cosmovisión indígena del buen vivir o sumak kawsay en quichwa. Como han mostrado distintos autores (Prada, 2011, p. 227; Medina, 2011, p. 39; Yampara, 2012, p. 65; Albó, 2011, p. 138; Gudynas \& Acosta, 2011, p. 71; Macas, 2010, p. 14), las traducciones al castellano no coinciden plenamente con la idea de vida buena que los movimientos indígenas de ambos países se encargaron de reconstruir en las últimas dos décadas. Sin embargo, en términos generales, el VBBV se ha concebido como una relación armónica entre seres humanos y entre ellos y la naturaleza. está catalogada como participante menor en el volumen global de emisiones de dióxido de carbono y otros gases contaminantes, hoy enfrenta crecientes problemas asociados a la extracción industrial de minerales, como la contaminación y la desecación de fuentes hídricas; los cambios climáticos que se expresan en fenómenos como el Niño y la Niña, los cuales afectan por intensos inviernos o largas sequías distintas zonas; la creciente contaminación del aire en los entornos urbanos; la deforestación de los bosques en función de la ganadería o la agroindustria; entre otros (Delgado, 2013; Seoane, 2012).

Todo ello hace imposible e indeseable que los países "subdesarrollados" continúen en su carrera por emular a los "desarrollados" en sus niveles de crecimiento, producción y consumo; de hecho, de acuerdo con los cálculos de Puente (2011, p. 358), se necesitarían por lo menos seis planetas con las características del nuestro para hacer posible ese sueño. Así, la crisis ambiental sería producto de esa forma de entender la "vida buena" $y$, consiguientemente, se hace necesario formular alternativas como el VBBV. Sin embargo, las distintas perspectivas sobre este concepto han suscitado un acalorado debate en América Latina, en el que con frecuencia las posiciones son extremas: o bien se acepta la necesidad de desarrollar este enfoque, asumiendo que es radicalmente contrario al desarrollo, o bien se lo rechaza de plano, exaltando sus deficiencias respecto a las distintas teorías comprendidas en el paradigma del desarrollo.

Este trabajo examina algunos tópicos de la discusión al ponderar las posibles contribuciones del VBBV a las sociedades latinoamericanas contemporáneas, pero resaltando también sus limitaciones en relación con las políticas económicas concretas. El argumento central puede sintetizarse de la siguiente forma: el VBBV tiene un horizonte normativo más ambicioso que el paradigma del desarrollo porque apuesta por una concepción distinta de la pobreza y la riqueza, una economía holística que comprenda también sus efectos sobre la naturaleza y permita transitar de la primacía del crecimiento económico y la eficiencia hacia la satisfacción de necesidades y el imperativo de la 
suficiencia, todo lo cual pasa por descolonizar los saberes de la economía.

No obstante, si bien el VBBV opera como una utopía con posibles consecuencias políticas, se caracteriza por un déficit de operacionalización que se manifiesta en la dificultad para definir políticas concretas e indicadores de medición precisos. Para desarrollar este argumento, en la primera parte, se reconstruyen los aportes del VBBV en un sentido normativo; mientras que en la segunda parte, se exponen las principales críticas que ha recibido así como sus dificultades de operacionalización.

\section{LOS APORTES NORMATIVOS DEL VIVIR BIEN Y DEL BUEN VIVIR}

El vivir bien (suma qamaña, en aymara) y el buen vivir (sumak kawsay, en kichwa) son cosmovisiones de los pueblos indígenas andinos, que han tratado de ser actualizados por intelectuales indígenas y mestizos como una alternativa al desarrollo, y que nacen justamente de la imposibilidad de traducir a las lenguas autóctonas ideas como las de progreso y desarrollo (Prada, 2011, p. 227).

En términos normativos, existe un consenso mínimo, entre intelectuales indígenas y mestizos, cuando se trata de definir el horizonte del VBBV. En ambos casos, se trata de conseguir la armonía entre los seres humanos y entre estos y la naturaleza, Pachamama o madre Tierra (Choquehuanca, 2010, p. 10; Acosta, 2012, p. 15). Entre los aportes normativos del VBBV se destacan su crítica del desarrollo, la formulación de una economía holística que comprenda sus efectos sobre la naturaleza y el esfuerzo por repensar las necesidades y descolonizar los saberes de la economía.

\section{La crítica del desarrollo}

Los teóricos del VBBV se han negado a ver en él una forma de "desarrollo alternativo" y han sostenido que se trata de una "alternativa al desarrollo" (Acosta, 2012, p. 68; Acosta, Martínez \& Sacher, 2013, p. 309). Este enfoque tiene una concepción distinta del progreso a la que predomina dentro del paradigma del desarrollo, que no pasa por el crecimiento económico, la producción y el consumo ilimitados. Esta concepción del progreso, asimismo, se sustenta en concepciones distintas de la probreza, la riqueza y la vida buena.

Las teorías del desarrollo se han sustentado en la idea de un progreso lineal necesario y deseable, basadas, a su vez, en el crecimiento económico, hasta el punto que autores como Rostow (1961) prácticamente establecieron una equivalencia entre ambos conceptos. Tal sinonimia tardó en cuestionarse y durante la mayor parte del tiempo la discusión se centró en el papel del Estado y el mercado en la promoción del desarrollo (Sen, 1998), aun cuando se aceptaba que el crecimiento económico no necesariamente se traducía en desarrollo (Casas, 2011, p. 331). De esa forma, incluso enfoques latinoamericanos como el estructuralismo, la teoría de la dependencia y el neoestructuralismo (Madoery, 2012) mantuvieron el crecimiento económico como un elemento necesario para alcanzar el desarrollo.

Durante los años noventa, el premio Nobel Amartya Sen formuló un enfoque que se esforzaba claramente por deslindar los conceptos de desarrollo y crecimiento. Sen empezó por concebir el desarrollo de una manera que no enfatizaba en el aumento de la utilidad marginal, sino como un progresivo ensanchamiento de las oportunidades de las personas para aprovechar sus capacidades. Por consiguiente, se impone la necesidad de relegar los indicadores de utilidad económica, como el crecimiento económico medido en términos del producto interno bruto (PIB) o el producto nacional bruto (PNB) para enfocar indicadores orientados al acceso a la salud, la educación o la equidad de género, entre otros. De acuerdo con Sen (2000, p. 16), el fin del desarrollo es aumentar las oportunidades de las personas o, en otras palabras, su libertad. Por tanto, el crecimiento no debe ser erigido como el objetivo último, sino debe comprenderse como un medio para eliminar las distinas constricciones o "faltas de libertad" (Sen, 2000, p. 19).

Hoy en día existen otros enfoques que han relativizado la importancia del crecimiento 
económico, como el desarrollo sostenible, el desarrollo humano, el desarrollo a escala humana $y$ el ecodesarrollo, entre otros (Elizalde, 2009; Unceta, 2009). No obstante, en todos los casos se presupone un crecimiento económico como factor necesario para el desarrollo (Gabbert, 2013, p. 431). Ninguno de los enfoques del desarrollo cuestiona de fondo las ideas de riqueza, probreza y buena vida predominantes, así como la idea de un progreso lineal necesario y deseable (Acosta, 2012, p. 42). El enfoque de Sen tampoco se aparta sustancialmente de supuestos centrales del paradigma del desarrollo como la visión lineal y evolutiva de la historia, el antropocentrismo o la concepción instrumental de la naturaleza (Gudynas, 2013, p. 439).

Estos supuestos son cuestionados por el concepto de VBBV, empezando por la distinción entre el "vivir bien" o el "buen vivir" y el "vivir mejor". EI VBBV no es una mejor forma de vida, pues ello implica que habrá una "peor" (Gudynas, 2011b, p. 233). De acuerdo con Choquehuanca (2010, p. 8), el "vivir mejor" implica necesariamente romper con el principio de convivencia y complementariedad entre los seres humanos y entre estos y la naturaleza, en la medida en que fomenta la competencia antes que la ayuda mutua, y el aprovechamiento del otro - ya se trate del prójimo o la naturaleza-, el egoísmo y el individualismo.

EI VBBV se aparta de la concepción lineal de la historia y el progreso, que supone el antropocentrismo entendido como la subordinación de la naturaleza a las necesidades y los intereses de los seres humanos, y sobre todo del concepto de buena vida fundado en el crecimiento económico, la producción y el consumo ilimitados (Albó, 2011, p. 135). Además, el "vivir mejor" implícito en la idea del desarrollo implica posponer el ideal de vida buena para el futuro, un futuro cada vez más incierto debido a la crisis ambiental; mientras el VBBV está orientado al presente, lo cual rompe con la idea lineal de la historia. Por consiguiente, la concepción de pobreza y de riqueza del VBBV es distinta. Aunque pasa por solucionar el creciente problema de la desigualdad material, no se reduce a la carencia de bienes materiales, sino que involucra la convivencia y la complementariedad entre seres humanos y la naturaleza (Gudynas, 2011a, p. 2).

\section{De una economía antropocéntrica a una economía holística}

El paradigma del desarrollo, incluso en sus perspectivas más heterodoxas como el desarrollo humano, está basado en un enfoque antropocéntrico, donde lo que se desarrolla son las potencialidades de los seres humanos y las sociedades, mientras la naturaleza es concebida como una fuente de recursos al servicio de sus necesidades e intereses (Zaffaroni, 2011, p. 37; Acosta, 2011, p. 321). En contraste, consciente de las limitaciones de una visión antropocéntrica para la actual crisis ambiental, el VBBV apuesta por cambiar la visión antropocéntrica por una visión holística donde la naturaleza, Pachamama o madre Tierra tiene un valor en sí misma, como elemento necesario para la vida, independiente de las valoraciones de los seres humanos.

La perspectiva antropocéntrica es incompatible con el objetivo de construir relaciones de convivencia y complementariedad con la naturaleza. La idea de progreso contenida en el paradigma del desarrollo pasa necesariamente por un creciente dominio y explotación de la naturaleza, bajo el supuesto de que el ser humano está separado de ella. En cambio, el VBBV, de acuerdo con el intelectual indígena ecuatoriano Floresmilo Simbaña (2011, p. 222), apuesta por recuperar otras formas de relación entre seres humanos y naturaleza presentes en las cosmovisiones de los pueblos indígenas andinos y americanos, en los que sociedad y naturaleza forman un todo que no es posible separar, y donde "la naturaleza no era un recurso, sino la Pachamama, la 'madre' de todo lo existente" (2011, p. 222).

Varios intelectuales indígenas concuerdan en esta perspectiva holística, que empieza por comprender que en la cosmovisión de los pueblos indígenas andinos, y en la de muchos americanos, no hay una concepción de la naturaleza como una cosa, como un objeto inanimado, sino que se 
considera que todo lo existente tiene vida (Oviedo, 2012, p. 53). La dirigente indígena ecuatoriana Nina Pacari explica que en "la cosmovisión indígena todos los seres de la naturaleza están investidos de energía que es el Samai y, en consecuencia, son seres que tienen vida: una piedra, un río (agua), la montaña, el sol, las plantas" (2009, pp. 33-34). El intelectual aymara Pablo Mamani sostiene que en el pensamiento aymara la muerte no existe como se concibe en Occidente:

[...] es otro momento de vida más porque se re-vive en las montañas o en las profundidades de los lagos o ríos. En realidad, los muertos se convierten en abuelos-abuelas, achachilas-abuichas. Los achachilas-abuichas son las montañas elevadas, o las montañas debajo del agua como ch'ua achachila-abuicha. Los muertos están cohabitando con los vivos. (Mamani, 2011, p. 69)

Los promotores mestizos del VBBV coinciden con la perspectiva holística. Para Acosta (2012, p. 88), se trata de abandonar la visión antropocéntrica para transitar hacia un enfoque "sociobiocéntrico", que no privilegie el bienestar de una especie determinada, sino de la vida en su conjunto. Ello implica también abandonar la perspectiva instrumental y utilitaria que ha guiado las relaciones entre seres humanos y naturaleza, para comprender que la naturaleza tiene un valor intrínseco independiente de las valoraciones subjetivas que puedan asignarle los seres humanos con arreglo a sus intereses o necesidades (Gudynas, 2011a, p. 3).

Este aspecto tiene un desarrollo mayor en el caso ecuatoriano, donde se ha transitado de los derechos ambientales, concebidos como parte de los derechos humanos y, por lo tanto, basados en una visión antropocéntrica, hacia los derechos de la naturaleza, lo que supone un enfoque biocéntrico donde la naturaleza adquiere el estatus de sujeto de derechos (Gudynas, 2009, p. 60). En efecto, en su artículo 71, la Constitución ecuatoriana establece que "la naturaleza o Pacha Mama, donde se reproduce y realiza la vida, tiene derecho a que se respete integralmente su existencia y el mantenimiento y regeneración de sus ciclos vitales, estructura, funciones y procesos evolutivos", en contraste con el caso boliviano donde se mantiene la referencia a los derechos y la justicia ambiental.

Adicionalmente, el reconocimiento de la Pachamama en el mismo nivel de la naturaleza se traduce en un reconocimiento de igualdad entre la cosmovisión occidental y la de los pueblos y nacionalidades indígenas. Sin embargo, más allá de las disposiciones jurídicas, en ambos casos el VBBV apuesta, en términos normativos, por avanzar desde un enfoque antropocéntrico hacia uno biocéntrico u holístico.

\section{Repensar las necesidades: de la primacía de la eficiencia al imperativo de la suficiencia}

Al igual que otras alternativas formuladas frente a la crisis ambiental, el VBBV intenta construir opciones para "modificar radicalmente el metabolismo socionatural" (Sempere, 2010, p. 8). Ello implica modificar los estilos de vida para hacer que la satisfacción de las necesidades humanas no amenace la preservación de la biósfera y de la propia vida humana. Tal cambio supone una transformación cultural, pues pasa por redefinir las necesidades, y socioeconómica, porque necesariamente implicará consumir, producir y contaminar menos, así como acoplar el sistema económico a las leyes de funcionamiento de la biósfera, que son su condición de posibilidad. Un primer paso en este sendero es transitar desde el énfasis en la eficiencia hacia un concepto de suficiencia.

La eficiencia, entendida como el cálculo de costo y beneficio que busca reducir costos y aumentar las utilidades en el menor tiempo posible, ha predominado en la economía moderna y en el paradigma del desarrollo. Siguiendo a Hinkelammert (2002, pp. 11-42), el problema de este tipo de racionalidad es que no permite evaluar las consecuencias no buscadas de la eficiencia. En otras palabras, existen unos "efectos indirectos de la acción directa" que no están comprendidos 
en la racionalidad predominante. Por ejemplo, las decisiones de los actores económicos, Estados, empresas e individuos no siempre tienen en cuenta en su análisis de costo y beneficio las consecuencias indirectas de sus acciones a mediano y largo plazo sobre el medio ambiente.

La racionalidad eficientista también contraría el principio de convivencia del VBBV, puesto que hace posible concebir a los otros, ya se trate de seres humanos o de la naturaleza, como medios y no como fines en sí mismos (Gudynas, 2011a, p 15). Además, dicha racionalidad fomenta la competencia que conlleva la devastación social y ambiental, haciendo imposibles las relaciones de cooperación y complementariedad, y fomentando la desigualdad entre ganadores y perdedores (Macas, 2010, p. 16).

El criterio de suficiencia propuesto por Acosta (2012) supone administrar los recursos actuales de tal manera que la satisfacción de las necesidades no atente contra la superviencia de la biósfera. Ello implica una modificación de los estilos de vida que necesariamente pasa por una transformación de las necesidades. En consecuencia, y como sostiene Sempere $(2009$, p. 66), supone transitar de una economía basada en las preferencias individuales, propia del enfoque marginalista, hacia una economía donde el centro de interés sea la satisfacción de necesidades. Al respecto, existen necesidades históricamente construidas que no deberían confundirse con las "preferencias", pues estas últimas pueden ser inducidas por el mercado a través de la publicidad (Sempere, 2009, p. 57).

Sempere $(2009,2010)$ se ha ocupado de reconceptualizar las necesidades. Para ello, empieza por realizar una crítica al supuesto de Max-Neff, Elizalde y Hopenhayn (1986, p. 27), quienes sostienen que existen necesidades humanas universales $y$ que lo único que cambia en el tiempo y el espacio son sus "satisfactores", herramientas, objetos, prácticas y relaciones necesarias para satisfacer las necesidades. Sempere (2010, pp. 163-165) distingue entre las necesidades fisiológicas, que tienden a ser universales, y aquellas denominadas psicosociales, además de las necesidades instrumentales. Las necesidades fisiológicas (comer, descansar, dormir) son interdependientes con las psicosociales, el conjunto de relaciones que se establecen para satisfacer las necesidades (seguridad, reconocimiento, pertenencia) y las instrumentales, los medios que en sí mismos no satisfacen una necesidad, pero ayudan a manipular el medio ambiente con miras a satisfacerla (herramientas, técnicas, tecnología). Finalmente, existe otro tipo de necesidades asociadas al potencial. Mientras las anteriores necesidades están asociadas a la carencia, las necesidades asociadas al potencial implican la oportunidad de realizar algo, participar, construir relaciones afectivas, entre otros, cuya satisfacción contribuye a la autorrealización, la autonomía y la libertad (Sempere, 2010, p. 6).

Para el VBBV, esta concepción de las necesidades tiene profundas consecuencias. Implica que las necesidades son social e históricamente construidas, lo cual también supone la posibilidad de transformarlas al tiempo que se transforman los sistemas sociotécnicos que se han creado para satisfacerlas (Sempere, 2010, p. 8). En segundo lugar, dado que las necesidades no son universales, sino que dependen de la historia particular de las sociedades y de las culturas, la construcción del VBBV o la modificación del sistema sociotécnico dominante pasa por poner en práctica una geometría variable que rechaza las fórmulas universales para construir la sociedad deseada.

\section{Descolonizar la economía}

Uno de los propósitos que se plantea el VBBV al recuperar las cosmovisiones indígenas de América es reivindicar los saberes subordinados, por lo que se percibe como la imposición de los saberes dominantes de las sociedades occidentales. No obstante, la descolonización por la que apuesta no supone la imposición de los saberes autóctonos de América sobre los demás, sino la construcción intercultural de un nuevo horizonte de vida buena.

Desde el famoso discurso de Harry Truman, el 20 de enero de 1949, el desarrollo se convirtió en un referente universal, pese a tener unos orígenes particulares en ciertas sociedades europeas $y$ 
norteamericanas. Desde entonces, se supuso que era necesario y deseable que todas las sociedades transitaran el mismo camino que estas sociedades habían previamente transitado con el objeto de convertirse en sociedades "desarrolladas" (Escobar, 2007, pp. 19-20). Por consiguiente, el desarrollo se impuso a las cosmovisiones y las formas de vida de otras sociedades, consideradas ahora como "subdesarrolladas", lo que constituye una forma de colonialismo o colonialidad (Quijano, 2007, pp. 93-94). El colonialismo impide que las culturas distintas, los "otros", puedan construir una imagen de sí mismos, una identidad, y se vean obligados a abrazar una identidad extraña (Zapata, 1997).

El paradigma del desarrollo asumió como el ideal de vida buena aquel basado en el crecimiento económico, la producción y el consumo ilimitados, orientado por una concepción de la pobreza y la riqueza restringida a la posesión y el disfrute de bienes materiales, que situó en la "periferia" o en el campo de los países "subdesarrollados" otros ideales de vida buena, al considerarlos inferiores o particulares frente a su carácter presuntamente "universal". En la visión lineal y progresiva de la historia inserta en el paradigma del desarrollo, para constituirse como "desarrolladas", las sociedades debían negar sus particularidades y sus propias expresiones culturales para aspirar a uniformizarse de acuerdo con el ideal de vida buena de las sociedades desarrolladas.

EI VBBV no apuesta por construir un mundo donde todas las sociedades abracen su ideal de vida buena, como el desarrollo, sino por construir ese ideal mediante el diálogo intercultural (Cruz, 2013). Esto descansa en la convicción de que todas las culturas y todas las sociedades tienen concepciones de buena vida que pueden entrar en un diálogo en igualdad de condiciones para encontrar soluciones a la actual crisis ambiental, como sostiene un intelectual indígena: "Todos los pueblos en su cosmovisión contemplan aspectos comunes sobre el Vivir Bien" (Huanacuni, 2010, p. 32).

El VBBV es en sí mismo una construcción intercultural, puesto que se alimenta de las distintas concepciones de vida buena de la diversidad de pueblos y culturas indígenas americanas, pero también inserta en su proyecto saberes mestizos y aquellos propios de la cultura occidental, como el saber científico. En este sentido, reivindica los saberes locales de las culturas indígenas, subalternizadas por los saberes dominantes, y cuestiona el colonialismo intelectual (Tortosa, 2012, p. 1), pero también apuesta por la "ecología de saberes" formulada por Santos (2010, p. 44). Esta perspectiva supone la complementariedad entre distintas formas de conocimiento bajo el postulado: "no hay ignorancia o conocimiento en general; toda la ignorancia es ignorante de un cierto conocimiento, y todo el conocimiento es el triunfo de una ignorancia en particular [...] La utopía del interconocimiento es aprender otros conocimientos sin olvidar el propio" (Santos, 2010, p. 44).

En fin, en contraste con el colonialismo propio del paradigma desarrollista, el VBBV no establece una norma universal a la que todas las sociedades necesariamente deben acoplarse, tampoco establece una jerarquización entre las distintas culturas, sino que apuesta por un diálogo entre ellas y entre sus distintas formas de conocimiento de cara a encontrar alternativas a la crisis ambiental contemporánea.

\section{LOS LÍMITES PRÁCTICOS DEL VIVIR BIEN- BUEN VIVIR}

Los críticos del VBBV han resaltado su carácter utópico y la poca concreción que adoptan sus postulados. Incluso para algunos autores, resulta un ejercicio estéril intentar revivir las cosmovisiones indígenas porque en la actualidad no son practicadas por la mayoría de las comunidades y porque, aunque lo fueran, estas formas de pensar no necesariamente se caracterizaron por la armonía en cuanto a la relación entre seres humanos y naturaleza. La escasa concreción del concepto acarrea el riesgo de convertirlo en una categoría "comodín" o de asumirlo como un dogma; además, presenta grandes problemas para proponer políticas concretas y dar respuesta a discusiones trascendentales 
en el contexto latinoamericano como la industrialización y el desarrollo tecnológico.

\section{Los riesgos del vivir bien-buen vivir}

Algunos autores han llamado la atención sobre el "retorno al pasado" que estaría implícito en la cosmovisión del VBBV. Desde esta perspectiva, existen dos argumentos críticos. Por una parte, se afirma que las comunidades indígenas de los Andes bolivianos y ecuatorianos desde hace más de un siglo no se rigen por los principios del VBBV; de acuerdo con Mansilla (2012, p. 18), es necesario hacer un análisis diferenciado de acuerdo con las distintas regiones donde habitan pueblos indígenas, pues en los Andes y el altiplano boliviano hace mucho tiempo no se practican los principios del vivir bien, que aseguraban una lógica de cierto respeto hacia la naturaleza, y las comunidades indígenas han sido ampliamente permeadas por la racionalidad moderna del análisis de costo-beneficio, por lo que ya no tienen como meta el "vivir bien", sino más bien el "vivir mejor" que tanto se critica.

Por otra parte, se afirma que el VBBV es un peligroso intento por revivir un pasado glorioso que nunca existió. Al respecto, el antropólogo ecuatoriano José Sánchez-Parga (2011, p. 34) sostiene que el VBBV no tiene ningún antecedente en la tradición andina, su influencia actual procede de una "inflación textual y discursiva", y se trata más bien de una "tradición inventada" que dudosamente puede dar respuesta a los complejos problemas del presente. Prueba de ello es que las relaciones de los seres humanos con la naturaleza en el contexto andino no se caracterizaron precisamente por la armonía con la que ahora quiere investirse el concepto, sino también por la domesticación muchas veces violenta y la explotación de la naturaleza en función de las necesidades y los deseos humanos (Sánchez-Parga, 2011, p. 38).

Los optimistas del VBBV han respondido a este tipo de críticas haciendo énfasis en el carácter normativo o prescriptivo, más que descriptivo y analítico, del concepto. Los intelectuales indígenas defienden la vigencia de ciertas prácticas del VBBV en sus comunidades. Además, si bien es un concepto que proviene de una "memoria larga" que se remonta a la época precolombina, consideran que puede actualizarse como una alternativa a la crisis del presente (Simbaña, 2011, p. 219). Si bien esta perspectiva recupera las cosmovisiones de las comunidades indígenas, no pretende un retorno a un pasado mitificado, tampoco supone que todas las culturas indígenas han convivido de forma respetuosa con el medio ambiente, pues históricamente hay casos de profundas modificaciones a este y en el diverso mundo indígena, hay distintas posiciones frente al problema, unas más respetuosas, otras más proclives a la manipulación (Gudynas, 2010, pp. 282-283). En fin, el VBBV pretende construir una forma alternativa de vida que no niega o rechaza las ventajas tecnológicas del mundo moderno, que son en sí mismas producto del aporte de distintas culturas (Acosta, 2012, p. 80).

Para autores como François Houtart (2011, p. 61), el VBBV requiere recuperar las prácticas de las comunidades no inspiradas en el ideal de progreso y acumulación infinita, pero sin llegar a idealizarlas como son hoy o, como se supone, lo fueron en la época precolombina. "Tampoco es una simple invitación para retroceder en el tiempo y reencontrarse con un mundo idílico, inexistente por lo demás. No puede transformarse en una suerte de religión con su catequismo y sus manuales" (Acosta, 2012, p. 66). Además, el proyecto no está circunscrito únicamente a las comunidades indígenas andinas, puesto que los mestizos también han contribuido a delimitar su significado e, incluso, como antes se mostró, los mismos intelectuales indígenas han afirmado que existen horizontes del VBBV en otras sociedades que es necesario poner a dialogar. Por esta razón, la dirigente indígena ecuatoriana, Blanca Chancoso, resalta la necesidad de la traducción entre las distintas culturas:

La propuesta del Sumak Kawsay es incluyente, tiene en cuenta a mujeres, niños, ancianos, indios, afros, mestizos, es para toda la sociedad. Más bien pueden traducirla desde su idioma y desde 
su cultura. Esta palabra no es solo para indígenas porque está en nuestro idioma, miremos más bien la interpretación que cada uno le puede dar en el marco del cambio para alcanzar el buen vivir. (Chancoso, 2010, p. 6)

No obstante, los animadores del VBBV han advertido sobre una serie de peligros que puede enfrentar este concepto. Una de las mayores amenazas es el uso simplista, "podría desembocar en un sumak kawsay 'new age', por lo que el Buen Vivir no sería más que otra moda, una de las tantas que ha habido" y se convertiría en un nuevo dogma (Acosta, 2012, p. 83). Pero si por un lado existe el peligro de intentar revivir un mítico pasado idealizado, por el otro también es palpable el intentar "modernizar" al VBBV, haciéndo de él una forma de desarrollo alternativo más que una alternativa al desarrollo (Gudynas, 2011a, p. 11).

\section{La falta de concreción}

Otra crítica fuerte al concepto de VBBV radica en afirmar que es utópico y carece de una visión práctica que fije en concreto las decisiones, las acciones y las políticas que sería necesario adoptar como alternativas al paradigma del desarrollo. Este postulado estaría soportado en dos tipos de argumentos. Primero, en una valoración negativa de la utopía que pone en duda su eficacia política como productora de transformaciones reales. Por ejemplo, Sánchez-Parga (2011, p. 31) considera que la utopía del VBBV tiene un carácter reaccionario, en tanto constituye una "retroproyección" que no moviliza las fuerzas del cambio, sino que, por el contrario, tiene como efecto ahondar en la convicción de que no parece haber alternativa:

El recurso a discursividades étnicas (pachamama, sumak kawsay) es portador de una utopía reaccionaria, que adopta una fórmula del pasado como proyecto futuro, y no tiene en cuenta las condiciones de posibilidad para transformar la realidad, en detrimento de lo que puede ser una utopía política, basada en una crítica teórica de la realidad para transformar sus condiciones de posibilidad. (Sánchez-Parga, 2011, p. 32)

En segundo lugar, se afirma que el VBBV está sustentado en una retórica mística y esotérica que ha impedido precisar sus conceptos y, por consiguiente, concretarlos en instrumentos, decisiones y políticas. Stefanoni $(2012$, p. 12) sostiene que el VBBV carece de propuestas alternativas consistentes. Sus propuestas no dan respuesta a problemas como el mercado, el trabajo, la innovación tecnológica, sino que se diluyen en "una retórica quasi mística en algunos casos o simplemente utópica/ altercivilizatoria en otros" (Stefanoni, 2012, p. 14). Desde su punto de vista, ello hace parte de una "pose de autencidad ancestral", que puede ser eficaz para seducir "turistas revolucionarios", pero es incapaz de ofrecer alternativas reales de desarrollo y democracia: "El discurso pachamámico nos ofrece una catarata de palabras en aymara, pronunciadas con tono enigmático, y una cándida lectura de la crisis del capitalismo y de la civilización occidental" (Stefanoni, 2011, p. 261).

En el mismo sentido, Mansilla llama la atención sobre el hecho de que los saberes ancestrales en los que afirma sustentarse el VBBV no se han explicitado y "permanecen en una nebulosa conceptual. Se supone que son verdades elementales, profundas y auto-evidentes, que en cuanto fundamentos de las culturas aborígenes no requieren de una explicación argumentativa y discursiva, típica de la lógica occidental" (2012, p. 18). Es la imprecisión conceptual lo que hace que los teóricos del VBBV no den respuesta sobre la manera de aplicar sus principios a la gestión de sociedades modernas y urbanas, lo cual implicaría ir más allá del carácter esotérico que ha adquirido su lenguaje.

Es cierto que el VBBV es una utopía, pues de acuerdo con Acosta (2012, p. 26), más que técnico, el problema de la actual crisis ambiental y civilizatoria es político y una forma de impulsar los procesos de cambio es a través de la construcción 
de utopías. En este sentido, pretende satisfacer "la imperiosa necesidad de impulsar en el mundo la vida armónica entre los seres humanos y de estos en la Naturaleza, una vida que ponga en el centro la autosuficiencia y la autogestión de los seres humanos viviendo en comunidad" (Acosta, 2012, p. 32). Ello pasa por superar los sistemas organizativos antropocéntricos y subordinar el sistema económico a las leyes de funcionamiento de los sistemas naturales, entre otras cosas.

Pero lo que se critica, más allá de la utopía en sí misma, es su eficacia política, en la medida en que los críticos suponen que es incapaz de articular acciones en favor del cambio. No obstante, estos críticos tienen razón en resaltar las limitaciones del VBBV en términos prácticos. Estas se pueden observar, principalmente, en dos sentidos: en cuanto a las políticas económicas alternativas y en relación con los instrumentos de medición de sus efectos.

\section{La carencia de políticas concretas}

Los teóricos del VBBV se han centrado en aclarar la utopía, esto es lo que habría que hacer para construir la sociedad anhelada, "lo que sería deseable" (Tortosa, 2011, p. 119). Pero han dejado sin resolver los instrumentos concretos, los medios y el cómo llegar allá. De hecho, este aspecto no ha pasado desapercibido por entusiastas del concepto, como Gudynas (2011a, p. 2), quien echa de menos las políticas concretas, los planes gubernamentales, los marcos normativos, entre otros, pues su ausencia puede conducir a repetir las estrategias convencionales del desarrollo objeto de su crítica.

En la literatura sobre el VBBV, quien más se ha preocupado de este problema es Alberto Acosta (2012, pp. 166-167). Su propuesta de transición desde la sociedad basada en el paradigma del desarrollo hacia el buen vivir se basa en el autocentramiento, concepto tomado de Jurgen Schuldt, que designa una "disociación selectiva y personal del mercado mundial", que empieza desde abajo y desde adentro, desde lo local hacia arriba, pero que puede tener un mejor desempeño si es apoyada por el Gobierno central.

La idea es desarrollar las fuerzas productivas endógenas, controlando los patrones de acumulación y consumo, acompañados de un proceso político de participación que construya "contrapoder" político y económico. La meta es frenar el modelo de acumulación basado en la extracción de materias primas, reducir el desperdicio y el consumo de energía, redistribuir el ingreso y la riqueza, cambiar los patrones tecnológicos incentivando las tecnologías locales y limpias (con reducidas emisiones de dióxido de carbono). Asimismo, se parte del hecho de que ni el mercado ni el Estado son soluciones por sí mismos, por lo que es necesario construir una sociedad de mercados, sin monopolios ni especuladores, complementaria con economías con el mismo nivel de desarrollo, que permitan rescatar otras lógicas económicas como las que practican las comunidades indígenas andinas (muchas veces basadas en el intercambio de valores de uso) pues los agentes económicos no solo actúan por el afán de lucro (Acosta, 2012, p. 184).

En esta perspectiva, el VBBV se familiariza con propuestas sobre el "poscrecimiento", el "crecimiento estacionario", el "desacoplamiento", e incluso el "decrecimiento", formulados en otros contextos (Sempere, 2010, p. 9; Dietz, 2013, pp. 474-475). No obstante, como ha anotado, entre otros autores, Unceta (2012, p. 92), estas propuestas adolecen de una excesiva generalidad. Por ejemplo, el decrecimiento es demasiado vago. No se precisa cuáles son las implicaciones concretas de esta propuesta, en qué sectores se aplicaría (disminuir la producción, su valor monetario, su componente físico), o hasta dónde es posible decrecer, para no decir en dónde es necesario decrecer, dado que no todos los países transitan por la misma situación y es seguro que si los países "subdesarrollados" no apuestan por el crecimiento en al menos algunos sectores de su economía, irán de mal en peor y no se conseguirá transitar de la primacía de la eficiencia al imperativo de la suficiencia.

Aún más, el proyecto del VBBV no se ha planteado los retos que implica un proceso necesario 
para satisfacer el imperativo de la suficiencia como es la industrialización, en aspectos tan básicos como: ¿es posible desarrollar este proceso sin afectar considerablemente el medio ambiente?, ¿es posible construir un mercado interno sin industria propia?, ¿cómo garantizar la transferencia o el desarrollo de tecnologías afines a los ideales del VBBV? De acuerdo con Stefanoni, "como no se incluye en la propuesta renunciar a los bienes de consumo tecnológicamente perfeccionados, bienes que no es posible construir en el marco de economías comunitarias, estas últimas dependerían indefectiblemente de los productos fabricados en la esfera capitalista" (2012, p. 15).

\section{La ausencia de indicadores del vivir bien- buen vivir}

Un problema subyacente es el de la medición del buen vivir, en la medida en que pretende desmarcarse del énfasis que el paradigma del desarrollo ha hecho del crecimiento económico y fundamentalmente de patrones de medida como el PIB o, en ciertos casos, el PNB. Por una parte, tal medición no podría reducirse a la obtención de bienes o servicios, puesto que la concepción de vida buena del VBBV no se reduce a ellos, y sus criterios de pobreza y riqueza no están enfocados en la posesión y el disfrute de bienes materiales. Por otra parte, el enfoque del desarrollo se ha concentrado en la medición del vivir mejor, acentuando la medida del crecimiento económico y la demanda agregada, y de la pobreza, con indicadores como el de necesidades básicas insatisfechas, más que del vivir bien o la buena vida.

Autores como Albó (2011, pp. 141-142) se inclinan por hacer funcionales al VBBV algunos de los indicadores que ya se han utilizado para medir el desarrollo, pero que provienen de enfoques que no reducen su concepto al de crecimiento económico, como el índice de desarrollo humano, formulado por Amartya Sen. No obstante, para Albó, se trataría de reformar este concepto sustrayéndolo del individualismo, para incluir medidas que hagan referencia no solo al bienestar individual, sino también a la forma como se desarrolla la convivencia entre distintos individuos y entre estos y la naturaleza.

Por consiguiente, plantea la necesidad de desarrollar indicadores de relaciones sociales, como algunos que actualmente utiliza el Programa de las Naciones Unidas para el Desarrollo (PNUD) para la gobernabilidad, entre ellos los indicadores de participación y estabilidad, así como algunos indicadores del desarrollo sostenible que sirven para observar las relaciones entre seres humanos y naturaleza. Además, sería necesario crear indicadores "afectivos" de convivencia, que no podrán definirse de forma universal y transcultural, sino que deberán responder a los contextos culturales específicos. Entre otros, no estaría mal emular los indicadores de felicidad del reino de Bután.

\section{COROLARIO}

Este artículo evaluó, desde una perspectiva normativa y práctica, el concepto de VBBV que ha cobrado relevancia en los debates sobre las alternativas a la crisis ambiental en América Latina. En este sentido, desde el punto de vista normativo, el VBBV puede aportar importantes elementos. Su crítica del desarrollo enfatiza en la necesidad de desvincular la concepción de vida buena de la visión lineal y progresiva de la historia, así como de las nociones de pobreza y riqueza fundadas en la acumulación y el uso de bienes materiales, el crecimiento, la producción y el consumo ilimitados. En su lugar, el VBBV apuesta por un ideal de sociedad fundado en la convivencia y la complementariedad entre los seres humanos y entre estos y la naturaleza, cuya realización no se deja para el futuro, sino que trata de realizarse en el presente con los recursos actuales.

A diferencia del paradigma del desarrollo, el VBBV plantea la necesidad de repensar los fines de la economía. Primero, apuesta porque el sistema económico se subordine a las leyes del sistema biofísico o de la naturaleza, como condición necesaria para no ahondar la crisis ambiental y poner en riesgo la vida y, por consiguiente, la existenicia del 
propio sistema económico. Segundo, se esfuerza por repensar los fines del sistema económico; particularmente cuestiona el énfasis en la eficiencia como criterio central y en la satisfacción de preferencias, y sugiere, en cambio, la necesidad de avanzar hacia una economía cuyo fin sea la satisfacción de necesidades, de tal forma que el actual sistema sociotécnico pueda transformarse para establecer la suficiencia como criterio ético del sistema económico. Finalmente, propugna por descolonizar los saberes económicos y sociales en general, de tal forma que los conocimientos producidos en distintos contextos culturales puedan entrar en diálogo en igualdad de condiciones.

Sin embargo, desde una perspectiva práctica, el VBBV presenta numerosas dificultades y enfrenta no pocos peligros. Su déficit de concreción en políticas y medios necesarios para realizar su ideal de sociedad puede llevarlo a convertirse en una categoría vacía o bien a adoptar políticas de desarrollo alternativo en lugar de erigirse en una altenativa al desarrollo. Los problemas de operacionalización son palpables, sobre todo, cuando se trata de pensar problemas nodales a los que el paradigma del desarrollo ha dado una respuesta, como los problemas de la industrialización, el desarrollo o la transferencia tecnológica e, incluso, los criterios de medición.

En cualquier caso, el VBBV se ha insertado en la discusión actual sobre las alternativas a la crisis ambiental. Como otras propuestas planteadas en contextos culturales distintos, presenta limitaciones y potencialidades que es necesario comprender en todas sus consecuencias, antes de reducir la discusión a una dicotómica toma de partido. 


\section{REFERENCIAS}

1. Acosta, A. (2011). Los derechos de la naturaleza. Una lectura sobre el derecho a la existencia. En A. Acosta y E. Martínez (Comps.), La naturaleza con derechos. De la filosofía a la política. Quito: Abya-Yala.

2. Acosta, A. (2012). Buen vivir Sumak Kawsay. Una oportunidad para imaginar nuevos mundos. Quito: Abya-Yala.

3. Acosta, A., Martínez, E. \& Sacher, W. (2013). Salir del extractivismo: una condición para el Sumak Kawsay. Propuestas sobre petróleo, minería y energía en Ecuador. En M. Lang, C. López y A. Santillana (Comps.), Alternativas al capitalismo del siglo XXI. Quito: Abya- Yala, Fundación Rosa Luxemburgo.

4. Albó, X. (2011). Suma qamaña = convivir bien. ¿Cómo medirlo? En I. Farah \& L. Vasapollo (Coords.), Vivir bien: ¿paradigma no capitalista? La Paz: Postgrado en Ciencias del Desarrollo-Universidad Mayor de San Andrés (Cides-UMSA).

5. Casas, M. (2011). Una mirada económica hacia el vivir bien. En I. Farah \& L. Vasapollo (Coords.), Vivir bien: iparadigma no capitalista? La Paz: Postgrado en Ciencias del Desarrollo-Universidad Mayor de San Andrés (Cides-UMSA).

6. Chancoso, B. (marzo de 2010). El Sumak Kawsay desde la visión de la mujer. América Latina en Movimiento ALAI. Alternativas Civilizatorias: los viejos nuevos sentidos de humanidad, XXIV(453).

7. Choquehuanca, D. (2010). Hacia la reconstrucción del vivir bien. América Latina en Movimiento, 452.

8. Cruz, E. (2013). Pensar la interculturalidad. Una invitación desde Abya-Yala/América Latina. Quito: Abya-Yala.

9. Delgado, G. (Coord.). (2013). Ecología política del extractivismo en América Latina: casos de resistencia y justicia medioambiental. Buenos Aires: Clacso.

10. Dietz, K. (2013). Reacciones emancipatorias frente a la crisis. En M. Lang, C. López \& A. Santillana (Comps.), Alternativas al capitalismo del siglo XXI. Quito: Abya-Yala, Fundación Rosa Luxemburgo.

11. Elizalde, A. (2009). ¿Qué desarrollo puede llamarse sostenible en el siglo XXI? La cuestión de los límites y las necesidades humanas. Revista de Educación, número extraordinario.

12. Escobar, A. (2007). La invención del Tercer Mundo. Construcción y deconstrucción del desarrollo. Caracas: Fundación Editorial el Perro y la Rana.

13. Gabbert, K. (2013). Hay que dejar de crecer. Acerca del poscrecimiento. En M. Lang, C. López, y A. Santillana (Comps.), Alternativas al capitalismo del siglo XXI. Quito: Abya-Yala, Fundación Rosa Luxemburgo.

14. Gudynas, E. (2009). La dimensión ecológica del buen vivir. Entre el fantasma de la modernidad y el desafío biocéntrico. Revista Obets, 4, 49-53.

15. Gudynas, E. (2010). Imágenes, ideas y conceptos sobre la naturaleza en América Latina. En L. Montenegro (Ed.), Cultura y naturaleza (pp. 267-292). Bogotá: Jardín Botánico José Celestino Mutis.

16. Gudynas, E. (2011a). Buen vivir: germinando alternativas al desarrollo. América Latina en Movimiento, 462.

17. Gudynas, E. (2011b). Tensiones, contradicciones y oportunidades de la dimensión ambiental del buen vivir. En I. Farah \& Vasapollo, L. (Coords.), Vivir bien: iparadigma no capitalista? La Paz: Postgrado en Ciencias del Desarrollo-Universidad Mayor de San Andrés (Cides-UMSA)-Plural.

18. Gudynas, E. (2013). Postextractivismo y alternativas al desarrollo desde la sociedad civil. En M. Lang, C. López \& A. Santillana (Comps.), Alternativas al capitalismo del siglo XXI. Quito: Abya-Yala, Fundación Rosa Luxemburgo. 
19. Gudynas, E. \& Acosta, A. (2011). El buen vivir más allá del desarrollo. Qué Hacer, 181.

20. Hinkelammert, F. (2002). El retorno del sujeto reprimido. Bogotá: Universidad Nacional de Colombia.

21. Houtart, F. (2011). El concepto de Sumak Kawsai (buen vivir) y su correspondencia con el bien común de la humanidad. Ecuador Debate, 84.

22. Huanacuni, F. (2010). Definición del vivir bien. En Buen vivir/vivir bien, filosofía, políticas, estrategias y experiencias regionales andinas. Lima: Coordinadora Andina de Organizaciones Indígenas (CAOI).

23. Lovelock, J. (2011). La tierra se agota. Bogotá: Planeta.

24. Macas, L. (2010). Sumak Kawsay: la vida en plenitud. América Latina en Movimiento, 452.

25. Madoery, O. (2012). El desarrollo como categoría política. Crítica y Emancipación, 7(IV).

26. Mamani, P. (2011). Qamir qamaña: dureza de "estar estando" y dulzura de "ser siendo". En I. Farah \& L. Vasapollo (Coords.), Vivir bien: iparadigma no capitalista? La Paz: Postgrado en Ciencias del DesarrolloUniversidad Mayor de San Andrés (Cides-UMSA).

27. Mansilla, H. (2012). La concepción del buen vivir en la ideologia gubernamental boliviana. Nueva Crónica y Buen Gobierno, 100.

28. Max-Neff, M., Elizalde, A. \& Hopenhayn, M. (1986). Desarrollo a escala humana una opción para el futuro. Santiago de Chile: Development Dialogue.

29. Medina, J. (2011). Acerca del Suma Qamaña. En I. Farah \& L. Vasapollo (Coords.), Vivir bien: iparadigma no capitalista? La Paz: Postgrado en Ciencias del Desarrollo-Universidad Mayor de San Andrés (Cides-UMSA).

30. Oviedo, F. \& Atawallpa, M. (2012). El posmoderno buen vivir y el ancestral Sumakawsay. En A. Guillén $\&$ M. Phelan, Construyendo el buen vivir. Cuenca: Pydlos Ediciones.

31. Pacari, N. (2009). Naturaleza y territorio desde la mirada de los pueblos indígenas. En A. Acosta \& M. Esperanza (Comps.), Derechos de la naturaleza. El futuro es ahora. Quito: Abya-Yala.

32. Prada, R. (2011). El buen vivir como modelo de Estado y modelo económico. En M. Lang \& D. Mokrani (Eds.), Más allá del desarrollo. Quito: Abya-Yala, Fundación Rosa Luxemburgo.

33. Puente, R. (2011). "Vivir bien” y descolonización. En I. Farah \& L. Vasapollo (Coords.), Vivir bien: iparadigma no capitalista? La Paz: Postgrado en Ciencias del Desarrollo-Universidad Mayor de San Andrés (Cides-UMSA).

34. Quijano, A. (2007). Colonialidad del poder y clasificación social. En S. Castro \& R. Grosfoguel (Eds.), El giro decolonial: reflexiones para una diversidad epistémica más allá del capitalismo global. Bogotá: Pontificia Universidad Javeriana, Siglo del Hombre Editores.

35. Rostow, W. (1961). Las etapas del crecimiento económico. México: Fondo de Cultura Económica.

36. Sánchez-Parga, J. (2011). Discursos retrovolucionarios: Sumak Kausay, derechos de la naturaleza y otros pachamamismos. Ecuador Debate, 84.

37. Santos, B. (2010). Refundación del Estado en América Latina. Lima: International Legume Database \& Information Service (Ildis).

38. Sempere, J. (2009). Mejor con menos. Necesidades, explosión consumista y crisis ecológica. Barcelona: Crítica.

39. Sempere, J. (2010). Autocontención: mejor con menos. En N. del Viso (Ed.), Enfoques sobre bienestar y buen vivir. Madrid: Centro de Investigación para la Paz. 
40. Sen, A. (1998). Las teorías del desarrollo a comienzos del siglo XXI. Cuadernos de Economía, 29.

41. Sen, A. (2000). Desarrollo y libertad. Barcelona: Planeta.

42. Seoane, J. (2012). Neoliberalismo y ofensiva extractivista. Theomai, 26.

43. Simbaña, F. (2011). El Sumak Kawsay como proyecto político. En M. Lang \& D. Mokrani (Eds.), Más allá del desarrollo. Quito: Abya-Yala, Fundación Rosa Luxemburgo.

44. Stefanoni, P. (2011). ¿Adónde nos lleva el pachamamismo? Tabula Rasa, 15.

45. Stefanoni, P. (2012). ¿Y quién no querría vivir bien? Encrucijadas del proceso de cambio boliviano. Crítica y Emancipación, IV(7), IV.

46. Tortosa, J. (2011). Cambios de época en la lógica del desarrollo. Debate, 84.

47. Tortosa, J. (2012). Sumak Kawsay, buen vivir, ialternativa al desarrollo? Recuperado de http://www.universitatdelapau.org/files/23-41201-document/sumak_kawsay_sant_cugat.pdf

48. Unceta, K. (2009). Desarrollo, subdesarrollo, maldesarrollo y posdesarrollo: una mirada transdisciplinar sobre el debate y sus implicaciones. Carta Latinoamericana, 7.

49. Unceta, K. (2012). Crecimiento, decrecimiento y buen vivir. En A. Guillén \& M. Phelan (Eds.), Construyendo el buen vivir. Cuenca: Pydlos Ediciones.

50. Yampara, S. (2012). Suma Qamaña, lo que se maneja como buen vivir. En N. Velardi \& M. Zeisser (Comps.), Anales seminario internacional Desarrollo Territorial y Extractivismo. Luchas y Alternativas en la Región Andina. Cuzco: Centro Bartolomé de las Casas.

51. Zaffaroni, E. (2011). La Pachamama y el humano. En A. Acosta \& E. Martínez (Comps.), La naturaleza con derechos. De la filosofía a la política. Quito: Abya-Yala.

52. Zapata, M. (1997). La rebelión de los genes. Bogotá: Altamir. 